\title{
El ascenso de García Albiol. Politización del discurso migratorio y aplicación de la teoría del agenda setting en las elecciones locales de 2011
}

\author{
Naiara Puertas Cartón \\ Periódico Noticias de Gipuzkoa. Sección «Edición y cierre» \\ naiarapuertas@gmail.com \\ Carles Samper Seró \\ Investigador independiente \\ carleshamlet@gmail.com
}

Recibido: 22-10-2013

Aceptado: 15-04-2015

\section{Resumen}

El presente artículo analiza, desde la perspectiva comunicativa, cómo líderes políticos y medios de comunicación hacen uso de una serie de herramientas técnicas y discursivas para insertar las atribuciones que se otorgan al fenómeno de la inmigración dentro del más amplio discurso preelectoral y electoral, nutriendo lo que hemos dado en llamar su politización.

El estudio se centra en dos localidades del denominado cinturón rojo de Barcelona (Badalona y L'Hospitalet de Llobregat), caracterizadas por muchos años de gobiernos municipales socialistas. Realiza un análisis de contenido y discursivo de su programación televisiva local en los tres meses anteriores a los comicios municipales de mayo de 2011.

Se trata de observar si, más allá del fenómeno como tal, es su gestión comunicativa, de los tiempos y el diseño de agendas y atribuciones, lo que posibilita la construcción de un tipo de discurso determinado. También se quiere describir qué estrategias y qué agentes activos pudieron dar lugar a que la inmigración se convirtiera en un tema tan central en la campaña en Badalona, pero no en L'Hospitalet, teniendo además en cuenta que, en aquellos comicios, en la primera localidad tuvo lugar un cambio de color político, mientras que en la segunda no. El objetivo final es evaluar la efectividad del discurso migratorio politizado para establecer el agenda setting, así como hacer una somera descripción de mecanismos que reproducen lo que el análisis crítico del discurso (ACD) llama racismo de élite.

Palabras clave: inmigración; elecciones; framing; priming; Badalona; L’Hospitalet; élite; racismo 
Abstract. The rising of Garcia Albiol: Politicization of the migration discourse and implementation of the agenda setting theory in 2011 local elections

This article takes a communication perspective to analyze how political leaders and media use different technical and discursive tools to situate the claims ascribed to the phenomenon of immigration within the broader pre-electoral and electoral discourse, nurturing what we have called its politicization.

The study focuses on two municipalities of the so-called red belt of Barcelona (municipalities surrounding the capital and generally ruled by the left): Badalona and L'Hospitalet de Llobregat, where the Socialist party has ruled locally for many years. It involves a discourse and content analysis of television broadcasts during the three months leading up to the local elections that took place in May 2011.

Our aim is to establish whether, beyond the phenomenon as such, the construction of a particular type of discourse is enabled by communication management in relation to timings and the design of agendas and claims. We also aim to describe which strategies and active agents may have resulted in immigration becoming a central issue in the electoral campaign in Badalona whereas not in L'Hospitalet, taking also into account the fact that the elections precipitated a change in government in the first municipality which did not affect the latter. The final objective is to evaluate the effectiveness of the politicized immigration discourse in agenda setting processes, and also to provide a brief description of those mechanisms that reproduce what Critical Discourse Analysis (CDA) has called elite racism.

Keywords: immigration; elections; framing; priming; Badalona; L'Hospitalet; elite; racism

\author{
Sumario \\ Introducción 3. Resultados \\ 1. Marco teórico y conceptual 4. Discusión y conclusiones \\ 2. Metodología Referencias bibliográficas
}

\title{
Introducción
}

El 28 de julio de 2015, en un momento especialmente convulso para la política catalana, Xavier García Albiol, a quien hacía pocas semanas y pese a haber ganado los comicios del 25 de mayo - mejorando en porcentaje de votos, a pesar de perder un concejal-, un pacto entre las fuerzas de izquierdas había desalojado de la alcaldía de Badalona, era nominado por el Partido Popular candidato a la Generalitat de cara a las elecciones del 27 de septiembre. Este premio no era casual: Albiol, pese a dedicarse a la política municipal, ya era conocido a nivel del resto del Estado por su duro discurso en temas de inmigración y por campañas que irremediablemente ponían el foco en este fenómeno, dejando de lado otras particularidades de la gestión municipal. La última tenía, de hecho, un lema tremendamente explícito: «Limpiando Badalona».

Pero la figura de García Albiol había emergido mucho antes de llegar a este escenario. Lo que el presente estudio se propone describir es la articulación del discurso acerca del fenómeno migratorio a nivel municipal en dos locali- 
Tabla 1. Porcentaje de población inmigrante según estadísticas de explotación del Padrón Continuo ${ }^{1}$

\begin{tabular}{ccc}
\hline Año & L'Hospitalet de Llobregat & Badalona \\
\hline 2003 & $10,48 \%$ & $6,25 \%$ \\
2007 & $19,88 \%$ & $12,31 \%$ \\
2011 & $22,55 \%$ & $14,84 \%$ \\
2014 & $20,28 \%$ & $13,55 \%$ \\
\hline
\end{tabular}

dades del cinturón rojo de Barcelona (Badalona y L'Hospitalet de Llobregat), mediante un análisis de las posturas y del uso de herramientas comunicativas de los líderes políticos municipales reflejadas en distintos programas de medios de comunicación también locales, de cara a los comicios municipales del año 2011. Se da la paradoja de que los resultados en dichas elecciones en Badalona y L'Hospitalet, siendo ciudades parecidas, fueron bastante diferentes. Ambas pertenecen al Área Metropolitana de Barcelona, figuran entre las cinco más pobladas de Cataluña y, como podemos observar en la tabla 1, han visto cómo el número de inmigrantes extranjeros en sus poblaciones respectivas ha ido creciendo tanto porcentual como absolutamente.

Para el Partido Popular de Cataluña (PPC), que hasta 2011 solo gobernaba en cinco municipios catalanes y únicamente contaba con 18 de los 135 escaños del Parlamento autonómico, conseguir la alcaldía de Badalona, tercera ciudad de la comunidad autónoma, en un contexto en el que además pasó a gobernar ocho municipios, supuso un hito. En el caso de L'Hospitalet, si bien se observa un retroceso de los socialistas en número de votos, estos no perdieron el bastón de mando pero, en general, los resultados de las municipales de 2011 supusieron un fuerte revés electoral para esta formación.

Considerando que la introducción y la gestión mediática del discurso acerca de la inmigración articula una parte importante de las propuestas generales del Partido Popular para Badalona, y partiendo de una posición de desventaja del PPC en términos de poder en toda Cataluña, la estrategia de su candidato Xavier García Albiol fue, por tanto, muy exitosa y, como veremos, fruto de un trabajo a largo plazo que incluso algunos de sus adversarios le reconocen. La trayectoria política del ya exalcalde de Badalona se remonta a 1989, año en que entró en las filas del PPC. Dos años después ya lideraba la candidatura de dicha formación a la alcaldía de Badalona y logró hacer entrar a su partido en el pleno por primera vez en la historia municipal desde el cambio de régimen. Desde 1991, García Albiol fue mejorando sus resultados elección tras elección hasta devenir alcalde de la ciudad durante el mandato comprendido entre 2011 y 2015.

Paralelamente a su labor como presidente del grupo municipal del Partido Popular, desarrolló distintas funciones dentro de la estructura del PPC. Así, fue vicesecretario de organización del partido en dos ocasiones (2000-2003 y

1. Datos de explotación más cercanos cronológicamente a las elecciones municipales de mayo de 2015. 
Tabla 2. Badalona. Resultados de los comicios municipales entre 2003 y 2015 en porcentaje de votos y en número de concejales

\begin{tabular}{|c|c|c|c|c|c|c|c|c|c|}
\hline & Particip. & Abst. & PSC & PP & CiU & ICV- EUiA & ERC & $\begin{array}{l}\text { Guanyem } \\
\text { Badalona } \\
\text { en Comú }\end{array}$ & C's \\
\hline 2003 & $52,35 \%$ & $47,65 \%$ & $\begin{array}{c}40,07 \% \\
(12)\end{array}$ & $\begin{array}{c}17,52 \% \\
\text { (5) }\end{array}$ & $\begin{array}{c}13,13 \% \\
\text { (3) }\end{array}$ & $\begin{array}{c}16,44 \% \\
(5)\end{array}$ & $\begin{array}{l}7,71 \% \\
(2)\end{array}$ & No concurre & $\begin{array}{c}\text { No } \\
\text { concurre }\end{array}$ \\
\hline 2007 & $46,02 \%$ & $53,98 \%$ & $\begin{array}{c}28,81 \% \\
\text { (9) }\end{array}$ & $\begin{array}{c}21.86 \% \\
(7)\end{array}$ & $\begin{array}{c}16,46 \% \\
\text { (5) }\end{array}$ & $\begin{array}{c}14,78 \% \\
\text { (5) }\end{array}$ & $\begin{array}{c}5,77 \% \\
(1)\end{array}$ & No concurre & No entra \\
\hline 2011 & $52,15 \%$ & $47,85 \%$ & $\begin{array}{c}27,05 \% \\
\text { (9) }\end{array}$ & $\begin{array}{c}33,48 \% \\
(11)\end{array}$ & $\begin{array}{c}12,55 \% \\
\text { (4) }\end{array}$ & $\begin{array}{c}8,9 \% \\
(3)\end{array}$ & No entra & No concurre & No entra \\
\hline 2015 & $57,53 \%$ & $42,47 \%$ & $\begin{array}{c}14,09 \% \\
\text { (4) }\end{array}$ & $\begin{array}{c}34,21 \% \\
(10)\end{array}$ & $\begin{array}{c}7,94 \% \\
\text { (2) }\end{array}$ & $\begin{array}{c}6,68 \% \\
(2)\end{array}$ & $\begin{array}{c}10,98 \% \\
\text { (3) }\end{array}$ & $\begin{array}{c}\text { (alcaldía) } \\
17,51 \% \\
\text { (5) }\end{array}$ & $\begin{array}{c}5,6 \% \\
(1)\end{array}$ \\
\hline
\end{tabular}

Tabla 3. L'Hospitalet de Llobregat. Resultados de los comicios municipales entre 2003 y 2015 en porcentaje de votos y número de concejales

\begin{tabular}{|c|c|c|c|c|c|c|c|c|c|c|c|}
\hline & Particip. & Abst. & PSC & PP & CiU & $\begin{array}{l}\text { ICV- } \\
\text { EUiA }\end{array}$ & ERC & C's & PxC & Ganemos & CUP \\
\hline 2003 & $54,81 \%$ & $45,19 \%$ & $\begin{array}{c}53,18 \% \\
(16)\end{array}$ & $\begin{array}{c}15,89 \% \\
(4)\end{array}$ & $\begin{array}{c}9,78 \% \\
(3)\end{array}$ & $\begin{array}{c}11,7 \% \\
(3)\end{array}$ & $\begin{array}{c}5,45 \% \\
\text { (1) }\end{array}$ & $\begin{array}{c}\text { No } \\
\text { concurre }\end{array}$ & $\begin{array}{c}\text { No } \\
\text { concurre }\end{array}$ & $\begin{array}{c}\text { No } \\
\text { concurre }\end{array}$ & $\begin{array}{c}\text { No } \\
\text { concurre }\end{array}$ \\
\hline 2007 & $46,69 \%$ & $53,31 \%$ & $\begin{array}{c}52,76 \% \\
(17)\end{array}$ & $\begin{array}{c}14,88 \% \\
\text { (5) }\end{array}$ & $\begin{array}{c}10,27 \% \\
\text { (3) }\end{array}$ & $\begin{array}{c}8,92 \% \\
\text { (2) }\end{array}$ & $\begin{array}{c}\text { No } \\
\text { entra }\end{array}$ & $\begin{array}{l}\text { No } \\
\text { entra }\end{array}$ & $\begin{array}{c}\text { No } \\
\text { concurre }\end{array}$ & $\begin{array}{c}\text { No } \\
\text { concurre }\end{array}$ & $\begin{array}{c}\text { No } \\
\text { concurre }\end{array}$ \\
\hline 2011 & $50,16 \%$ & $49,84 \%$ & $\begin{array}{c}38,85 \% \\
(13)\end{array}$ & $\begin{array}{c}18,57 \% \\
(6)\end{array}$ & $\begin{array}{c}12,3 \% \\
\text { (4) }\end{array}$ & $\begin{array}{c}8,91 \% \\
\text { (2) }\end{array}$ & $\begin{array}{l}\text { No } \\
\text { entra }\end{array}$ & $\begin{array}{l}\text { No } \\
\text { entra }\end{array}$ & $\begin{array}{l}7,32 \% \\
\text { (2) }\end{array}$ & $\begin{array}{c}\text { No } \\
\text { concurre }\end{array}$ & $\begin{array}{l}\text { No } \\
\text { entra }\end{array}$ \\
\hline 2015 & $53,42 \%$ & $46,58 \%$ & $\begin{array}{c}33,24 \% \\
(11)\end{array}$ & $\begin{array}{c}9,93 \% \\
(3)\end{array}$ & $\begin{array}{l}5,99 \% \\
\text { (1) }\end{array}$ & $\begin{array}{c}10,22 \% \\
\text { (3) }\end{array}$ & $\begin{array}{l}8,97 \% \\
\text { (2) }\end{array}$ & $\begin{array}{c}13,24 \\
(4)\end{array}$ & $\begin{array}{l}\text { No } \\
\text { entra }\end{array}$ & $\begin{array}{c}7,47 \% \\
\text { (2) }\end{array}$ & $\begin{array}{l}5,11 \% \\
\text { (1) }\end{array}$ \\
\hline
\end{tabular}

2005-2008) y director de la campaña electoral del PPC durante las elecciones generales de 2008. Recientemente, vio aumentada su proyección política con su nombramiento como candidato del PPC a la Generalitat de Catalunya en las elecciones del 27 de septiembre de 2015, aunque la formación consiguió un mal resultado: once escaños.

Una vez contextualizado García Albiol, observemos en la tabla 2 la evolución de los resultados electorales de las formaciones políticas de ambas ciudades en porcentaje de votos y número de concejales (entre paréntesis). Los sombreados más oscuros corresponden a la formación ganadora en cada caso.

Nos proponemos hacer una descripción de cómo el modo en que el fenómeno de la inmigración aparece retratado en intervenciones y en discursos de líderes políticos de los medios locales hace que, en Badalona, el tema ocupe la centralidad de la campaña de 2011 — puesto que todas las formaciones, directa o indirectamente, resaltan el debate como decisivo-, mientras que en L'Hospitalet no. Dependiendo del contexto de la localidad a la que nos 
refiramos, medios o partidos políticos tratan de sacar el máximo beneficio bien de mantener el debate candente, bien de intentar minimizarlo para no entrar en puntos de fricción.

Parte de la postura de estas formaciones viene dada por sus posiciones políticas. Describiremos los idearios de aquellas con un papel más destacado durante la campaña de los comicios de 2011. El PSC es un partido socialdemócrata que, aceptando las reglas económicas del sistema actual, hace hincapié en la promoción de políticas de ayudas sociales con fondos públicos. El PPC es un partido conservador interesado en la aplicación de políticas económicas neoliberales y con una clara identidad nacional española. CiU es una coalición de dos partidos (disuelta después de los comicios municipales de 2015), uno cristianodemócrata y otro liberal en lo económico, con un gran peso de la identidad catalana y con una tendencia a reivindicar el independentismo que ha ido creciendo. ICV-EUiA es otra coalición, aunque esta vez de partidos de izquierdas con vocación estatalista y con un interés especial por el desarrollo de importantes instrumentos gubernamentales para combatir la desigualdad social. ERC es un partido de tradición republicana, claramente independentista y con un énfasis en los temas sociales ligeramente de izquierdas. Por último, PxC es un partido conservador basado principalmente en su discurso antiinmigración, plasmado en su lema «Primer els de casa».

En cuanto a los resultados, queda patente el enorme ascenso del PPC en Badalona, de casi doce puntos y cuatro escaños (más de un 50\% superior a 2007), que, además, coincide con un aumento de más de seis puntos en la participación. Es la formación que recoge más sufragios de sus competidores, mientras que su mejora de resultados en L'Hospitalet, aunque también relevante, es más modesta. Asimismo, podemos concluir que mientras en Badalona el PSC mantiene su proporción de voto, en L'Hospitalet la pierde en favor del ascenso de casi todo el resto de fuerzas y le es arrebatada la mayoría absoluta en un bastión histórico.

Al tratarse el voto de un fenómeno multicausal, decir que únicamente la gestión sobre el discurso de la inmigración ha decantado el resultado sería muy arriesgado, además de que dicha aseveración requeriría un diseño de investigación distinto - como un estudio de panel o entrevistas - y acaso inviable, toda vez que los acontecimientos pertenecen al pasado. Pero lo que sí se puede hacer es una descripción de lo que llega a los electores a través de los medios de comunicación locales y, basándonos en las teorías que emanan del agenda setting y en otras técnicas como el framing y el priming, ver hasta qué punto las tácticas de politización discursiva de un tema resultan eficaces.

\section{Marco teórico y conceptual}

\subsection{El término politización}

Si por algo se caracteriza el uso del término politización en las ciencias sociales es por la variedad de temas en relación con los que se utiliza y por la falta de 
una definición estandarizada. Si bien es cierto que dicha palabra ha hecho fortuna con el significado de 'dar tintes políticos a asuntos que el sentido común asume que podrían gestionarse de un modo técnico' (por ejemplo: politización del calentamiento global), no existe un consenso acerca de su definición.

Ya en 1992, el libro de Bartram Brown The United States and the Politicization of the World Bank trata de explicar cómo afecta el proceso de politización a las actividades de las organizaciones internacionales y al derecho internacional. Define el incremento de la politización como un proceso por el cual actores de alto nivel político empiezan a implicarse en decisiones que, tiempo atrás, eran tomadas enteramente en instancias meramente técnicas o que resultaban de la interacción de las fuerzas del mercado. Si bien es cierto que el autor pide que no se asuma de un modo simplista que la politización supone intromisión de los políticos en asuntos otrora técnicos, sí hace hincapié en la existencia de factores políticos que condicionan la estructura de las relaciones entre las actividades económicas y otras que, a priori, no son políticas (Brown, 1992: 13).

En una línea parecida, en el campo de las relaciones internacionales, Mark Duffield (2004: 125), en Global Governance and the New Wars, habla de la politización del discurso del desarrollo como un cambio desde un análisis meramente técnico, apolítico y multicausal, que considera los desplazamientos de población como una consecuencia de la interacción de la pobreza con la lucha por los recursos y con unas instituciones débiles, hacia otro que introduce dimensiones morales y relativas a los derechos humanos. Afirma que la confusión entre acción humanitaria y política es un reflejo de la fusión entre desarrollo y seguridad, y señala que la ayuda no es un sustituto de la acción política.

Un campo que ofrece mayor paralelismo con el uso que hace del término politización con el propio del discurso migratorio es el cultural. Susan Wright (1998: 15) señala que las nuevas definiciones de cultura obligan al posicionamiento político de los antropólogos para establecer y desafiar los procesos de dominación y marginación, justo al contrario de lo que ocurría antes, cuando estos usaban la antigua idea de cultura, entendida como clasificación objetiva de la gente, precisamente para distanciarse de la política. Igualmente, apunta al uso de la cultura con fines políticos, algo parecido a lo que aquí identificamos como uso del discurso migratorio como parte del planteamiento electoral. La politización sería, pues, un proceso no casual, sino con una finalidad concreta. También se hace eco del hecho de que los políticos de la nueva derecha anglosajona se apropiaran de una nueva idea de cultura y la convirtieran en eufemismo de raza.

Otra definición interesante es la de Buonfino, que asocia, sin indicarlo expresamente, el término politización a la construcción política y social de la inmigración. En términos gramscianos, identifica dos discursos, uno hegemónico y otro antagonista, y su interrelación con la gestión pública de los flujos migratorios. Sostiene que la politización estaría relacionada con la expresión 
de un problema o de un hecho nuevo - inmigración en este caso-, y surge cuando el juego de interacción de actores (medios de comunicación, opinión pública y gobierno) genera un discurso hegemónico, aunque no único. La autora considera que, de las diferentes posiciones frente al hecho migratorio, derivan dos tipos de discursos: securitization (control de fronteras, posibles peligros derivados del mismo, etc.) y economization (posibles bondades), con lo cual se retroalimentan políticas y discurso. Por relacionarlo con lo mencionado en el campo cultural, vemos que la politización solo puede tener lugar en ámbitos de discurso plural, esto es, en esa esfera de interacción y de contraposición de intereses que es la opinión pública.

\subsection{La perspectiva del análisis critico del discurso, el racismo de élite como politización y la problematización del fenómeno migratorio}

Asimismo, para analizar la politización discursiva, es útil la perspectiva del análisis crítico del discurso (ACD), que permite estudiar eficazmente diversas formas de desigualdad social, fijándose, además, en otras dimensiones semióticas y enfocando el rol del discurso hacia el estudio de las relaciones de poder, dominación y desigualdad, así como hacia la manera en que los integrantes de un grupo social las reproducen u oponen resistencia a ellas. También trata de revelar lo implícito y de desvelar estrategias de manipulación, legitimación, creación de consenso y otros mecanismos discursivos que influyen en el pensamiento (e, indirectamente, en las acciones), en beneficio de los más poderosos (Van Dijk, 1997: 16-17), que son quienes propician la reproducción del racismo en toda la sociedad mediante la preformulación de las formas populares de racismo (2003a: 29). De hecho, Van Dijk (1997: 69) advierte de que buena parte del impacto del análisis crítico de noticias se centra en el proceso de producción, y es aquí donde el poder y la ideología desempeñan su papel más tangible, funcionando tanto interna (la estructura jerárquica de los equipos editoriales) como externamente (la dialéctica de poder entre los menos poderosos y los más poderosos, las fuentes de información y los actores de las noticias). El proceso productivo, los contactos formales e informales hasta redactar la pieza final, quién se considera una fuente fidedigna, etc. son aspectos a tener muy en cuenta. No podemos obviar que las piezas informativas - y más si cabe aún las de campaña electoral, en las que el emisor tiene absoluta preponderancia - son mecanismos de reproducción sociocultural.

Otro factor que casa con el racismo de élite lo encontramos en el cambio que surge en la percepción de la inmigración, y el paso desde la aprobación de la misma a su calificación como problema desde que, a principios de 1990, comenzara la serie de encuestas de actitudes ante la inmigración del CIS. La imagen del fenómeno queda vinculada a la generación de problemas sociales, el inmigrante pasa a ser considerado una amenaza en el ámbito laboral o de recepción de derechos sociales, además de en lo concerniente a la seguridad ciudadana y al deterioro de la convivencia social (Cea D'Ancona y Valles, 2010: 426). 


\subsection{La politización del discurso. ¿Por qué algunos partidos tienen más éxito que otros en la introducción de materias en los medios de comunicación?}

La idea de relación entre la agenda política y la agenda mediática tiene que ver con el contacto existente entre los partidos y los medios de comunicación de masas. Varios estudios (Van Aelst y De Swert, 2009; Walgarve y Van Aelst, 2006, citados en Hopmann et al., 2010) están de acuerdo en que la interrelación entre partidos y medios en tiempos electorales varía. El tratamiento que académicamente se ha dado a esta relación es el de tomar en consideración las campañas electorales como eventos y no como procesos (Brandenburg, 2002: 40, citado en Hopmann et al., 2010), dejándose de lado la relación, más informal si se quiere, entre partidos y medios al margen del periodo electoral. Esta relación anterior tiene impacto en la introducción de cuestiones por parte de los partidos en la agenda mediática y, por ende, social, a lo que se añade el propio sesgo inherente al proceso de producción que favorece la presencia de las élites en la rutina informativa y que en absoluto coincide con la perspectiva de los eventos tal y como son concebidos por los grupos minoritarios y sus miembros (Bañón et al., 2007: 31).

La evidencia empírica constata la existencia de una alta correlación entre las agendas de los partidos políticos y las de los medios de comunicación durante las campañas electorales (Díez Nicolás y Semetko, 1999, citado en Hopmann et al., 2010), pero no todos los partidos tienen el mismo éxito en lograr la entrada de sus asuntos preferentes en la agenda. Los resultados empíricos de algunos estudios señalan que, durante las campañas electorales, el partido que gobierna es quien tiene preeminencia en la agenda, porque, al gobernar, además, tiene la potestad de actuar o de haber actuado en la materia (Schönback y Semetko, 1996 y 2000, citados en Hopmann et al., 2010). Sin embargo, esto no explica por qué otros candidatos que no gobiernan tienen éxito en la introducción de su discurso en los medios. Nuestra hipótesis es que, dentro de un marco como es el de la campaña electoral, en el que saben que su discurso tendrá preeminencia sobre el de otros en determinadas materias, utilizan mecanismos de politización eficaces — especialmente el marcaje de la agenda-, incardinan sus afirmaciones en una suerte de "sentido común» que emana del racismo de élite y aprovechan la catalogación de ciertos fenómenos como problemas en barómetros sociológicos. Todo ello con la finalidad de encuadrar no solo su campaña, sino también la de sus contrincantes.

Concluyendo, la relación entre partidos y medios de comunicación es clave para determinar la relevancia de un asunto. Ya no es solo la voluntad del partido de introducir un tema determinado en los medios, sino que la relevancia del mismo está determinada por los mecanismos que vamos a exponer a continuación.

\subsection{Los mecanismos mediáticos de la politización: agenda setting, priming $y$ framing}

Ya hemos señalado que la idea de politización es, entre otras cuestiones, fruto de interacciones y de retroalimentación en una esfera pública plural. Con todo, 
hay que tener en cuenta que agenda setting, framing y priming son términos aún en construcción y en continua discusión, especialmente el segundo. El hecho de que autores como Kim et al. (2002) aboguen por la redefinición de los mismos da una idea de la complejidad de ajustarlos a un marco teórico. No vamos a ahondar mucho en los mencionados debates, sino que trataremos de utilizar las definiciones que creemos más pertinentes de cara a la metodología posterior. En todo caso, lo que nos interesa es que los tres mecanismos que describiremos a continuación articulan la politización discursiva en los medios.

\subsubsection{Agenda setting: no qué pensar, sino acerca de qué}

A modo de primera definición, la hipótesis básica del agenda setting - o 'configuración de la agenda'- es que la relevancia de los asuntos de la agenda mediática influye en la envergadura de las cuestiones en la agenda pública, esto es, en la mente de los votantes (Hopmann et al., 2010). Existiendo suficiente evidencia empírica, también está probado que la relevancia de los asuntos puede influenciar la elección de votantes objetivo por parte de los partidos (Brandenburg, 2002; Green y Hobolt, 2008; Kleinnijenhuis y De Ridder, 1998, citados en Hopmann et al., 2010), dado lo cual, como es lógico, las formaciones tratarán de, si no controlar, sí al menos influenciar la agenda mediática, proceso que ha sido descrito como agenda building - $\mathrm{O}$ 'construcción de la agenda' - (Brandenburg, 2002; Dearing y Rogers, 1996; Walters et al., 1996 y Weaver et al., 2004, citados en Hopmann et al., 2009).

La agenda política trabaja con conjuntos de temas que considera de importancia para el ciudadano. En este sentido, en el estudio más famoso sobre configuración de la agenda, McCombs y Shaw (1972: 176) determinan la responsabilidad que tienen los medios de comunicación a la hora de seleccionar los asuntos que constituyen la realidad política. Según señalan, los redactores, editores y productores son claves a la hora de perfilarla, ya que la audiencia no solo toma nota de los asuntos que son importantes, sino que la cantidad de información que se proporciona acerca de un tema, así como la posición en la que este aparece en un informativo, determina qué es relevante y qué no, lo cual configura la agenda. Enlazan con las ideas de Lang y Lang (1966: 466, citado por McCombs y Shaw, 1972: 176), que indican que los medios de comunicación de masas atraen la atención sobre determinadas cuestiones, además de sugerir sobre qué asuntos se han de tener opiniones o conocimientos.

Asimismo, McCombs y Shaw toman la idea de Cohen de que los medios pueden no tener éxito en decirle a la gente qué pensar, pero sí acerca de qué pensar (1963: 120, citado por McCombs y Shaw, 1972). Volvemos a lo mencionado más arriba sobre la retroalimentación en el proceso: si bien es cierto que el ciudadano tiene capacidad para plantear sus problemas a los agentes políticos, igualmente lo es que el modo en el que piensa acerca de ellos está condicionado no solo por su día a día, sino también por la visión del mundo - tanto acerca de los asuntos relevantes como acerca de cómo los partidos políticos los abordan- que le ofrecen los medios de comunicación. También Van 
Dijk, pero desde la perspectiva del ACD, apuntala este tema indicando que, en lugar de "transmitir» la creencia dominante de modo directo, los medios de comunicación constituyen una estructura interpretativa, que no se limita a transmitir o prescribir «aquello» que la gente debería pensar, sino "cómo» debería hacerlo. En otras palabras, los medios no solamente delimitan las fronteras, sino que también aportan el material de construcción para el consenso público. De este modo, fijan las condiciones de establecimiento y mantenimiento de una hegemonía ideológica (Van Dijk, 1997: 70).

No en vano, Iyengar y Kinder (1987), tras realizar diversos experimentos en Estados Unidos, concluyen que el modo en el que los norteamericanos ven la sociedad está muy definido por las historias que se reflejan en las noticias nocturnas. Si un informativo en particular se edita de modo que ensalza un determinado asunto - situándolo al principio del conjunto de noticias $\mathrm{u}$ otorgándole más tiempo que a otros-, los sujetos con quienes se experimenta darán mayor importancia a ese tema que antes del proceso.

Incluso partiendo de la premisa de que hay muchísimos temas que los ciudadanos no conocen de primera mano, y cuya opinión está totalmente influida por lo que señalan los medios, otra proposición del agenda setting relevante para esta investigación es que la gente que vive ciertos problemas en su día a día está lógicamente más inclinada a verlos como más relevantes que otra gente que no los vive. El análisis de Iyengar y Kinder se centra en elecciones presidenciales americanas, con una carga de materias mucho mayor que la de unas elecciones locales. Por tanto, en estas últimas, la experiencia personal del votante potencial condiciona mucho más su decisión final de voto, y el modo en el que esos asuntos se le presentan puede corroborar esa experiencia personal e, incluso, otorgar legitimidad política a las actuaciones de varios agentes (Iyengar y Kinder, 1988: 112-114). Además, y para la temática que nos ocupa, se ha demostrado la existencia de correlación positiva entre el número de noticias publicadas en la prensa nacional de mayor divulgación y el porcentaje de encuestados por el CIS que determinan que la inmigración constituye un importante problema (Igartua et al., 2004, citado por Cea D’Ancona y Valles Martínez, 2010), planteamientos acordes con la perspectiva del agenda setting que plantea que el énfasis puesto en ciertas cuestiones puede generar la llamada alarma social (Cea D'Ancona y Valles Martínez, 2010: 481).

\subsubsection{La noción de framing y su relación con el segundo nivel del agenda setting: quépensar}

Definiremos framing —o encuadre- del modo en que lo hacen Shoemaker y Reese (1996, citado por Scheufele y Tewksbury, 2007), esto es, como el modo en el que los comunicadores presentan la información para que la audiencia pueda relacionarla con esquemas previos y subyacentes. Recordemos lo señalado anteriormente acerca de la capacidad de los medios de no decir a la gente qué pensar, pero sí acerca de qué pensar. La literatura habla de un segundo nivel de configuración de la agenda que va más allá de examinar cómo la 
cobertura de los medios define cuáles son los temas sobre los que la gente piensa. Este segundo nivel se refiere a lo atribuido específicamente a una materia y a cómo estas atribuciones afectan a la opinión pública. A este respecto, Ghanem (1997: 4) lanza dos hipótesis: la primera, que los atributos acerca de una cuestión reflejada en los medios determinan el modo en el que el público piensa acerca de ese tema, y la segunda, que esos atributos, además, afectan a la relevancia de esa cuestión en la agenda pública.

Por lo tanto, este segundo nivel consiste en que no solo se introduzcan ciertos asuntos en la agenda mediática, como ocurría en el primer nivel (el sobre qué pensar que señalaba Cohen), sino que, además, los medios, en colaboración con los partidos y los agentes sociales, nos indican qué pensar acerca de los mismos. De esa primera agenda que se limitaba a introducir contenidos, nos movemos a otra más compleja, con una función más formadora de la opinión pública: el attribute agenda setting. La hipótesis, en este caso, es que ciertos atributos que son ensalzados en la cobertura mediática tomarán preeminencia también en la mente del público (Golan y Wanta, 2001; McCombs, 1997, citados en Kim et al., 2012). Así, las cuestiones a las que se otorga mayor relevancia también pasan a tener prioridad en la mente del votante y en sus juicios sobre los actores políticos (Kim et al., 2012: 44) y, por ende, en la conformación de la opinión pública.

Existe actualmente un intenso debate acerca de si este segundo nivel del agenda setting se puede asimilar a la noción de framing o 'encuadre'. Autores como Weaver, McCombs y Shaw ven el framing y también el priming como extensiones naturales del agenda setting, definiendo el segundo como la selección de un número restringido de atributos temáticos a incluir en la agenda de medios cuando nos referimos a un tema en particular y abogando incluso por la sustitución del término framing por attribute agenda setting. Sí es cierto que hay definiciones como la de Entman (1993) similares a la del attribute agenda setting, que considera el framing como un proceso de selección de ciertos aspectos de la realidad para hacerlos más destacados. Sin embargo otras, como la de Iyengar (1991), son distintas, porque distinguen el framing entre episódico y temático; o la de Gamson y Modigliani (1989), quienes lo definen como la presentación interpretativa de un relato.

El framing se asocia sobre todo a una idea de selección. Como indica Sádaba (2006: 121), las noticias casi siempre definen la realidad, tanto por lo que seleccionan como por lo que dejan de seleccionar. Hay que señalar que el encuadre es multinivel y que no tiene porqué obedecer a un ánimo deliberadamente manipulador ni de los políticos ni de los medios de comunicación. El político presenta ciertas situaciones enmarcadas de modo que su propuesta parezca la mejor para tratar ciertos problemas o gestionar realidades cambiantes, pero el medio de comunicación puede presentar esa intervención del político con arreglo a su propia línea editorial. En última instancia, el espectador interpreta toda esa información relacionándola con el conocimiento que tiene de la realidad —indudablemente condicionada por su consumo mediático-, con su propia ideología o con su visión del mundo. 


\subsubsection{Priming: redefiniendo el modo de valorar}

El priming, concepto surgido en la psicología cognitiva, puede definirse, aplicado al campo mediático, como un cambio en los estándares que la gente utiliza para realizar sus juicios políticos (Iyengar y Kinder, 1987: 63). En otras palabras, el priming en la esfera política supone que las noticias televisivas tienen la capacidad de modificar los índices de valoración del público (Freidenberg et al., 1999). El contenido noticioso, según señalan Scheufele y Tewksbury (2007: 11), da pie a la audiencia piense que debe juzgar la actuación de un dirigente o de un gobierno en función de ciertos asuntos que sirven como referencia. Así, características que se enfatizan en la cobertura noticiosa y que se convierten en relevantes en la mente de los individuos (attribute agenda setting) también funcionan como una importante dimensión evaluativa entre el público (attribute priming) de los líderes en campaña (Kim et al., 2012: 45). De hecho, es esto último lo que los partidos tratan de conseguir a la hora de pedir el voto.

Iyengar y Kinder (1987: 114) apuntan que este instrumento presume que, a la hora de evaluar fenómenos políticos complejos, las personas no toman en consideración todo lo que saben - ni siquiera cuando se trata de una cuestión que, por la razón que fuese, están motivadas a conocer-. Lo que sí ocurre, en cambio, es que consideran lo que ellos llaman «pequeños elementos de memoria política» que vienen a la mente y son accesibles. A través del priming, las noticias televisivas establecen los términos en los que se realizan tanto las valoraciones políticas como la toma de decisiones.

Los experimentos recogidos en su obra News that matters dan a entender que el efecto del priming es más intenso cuando se centra en las acciones de una persona (en este caso, las de los presidentes del gobierno estadounidense), en la cual resulta sencillo "concentrar» la responsabilidad sobre un tema en particular, que cuando se da en otros agentes que pueden resultar más difusos. Sin embargo, estudios posteriores, como los de Price y Tewksbury (1997), sostienen que no hay razón para pensar que otros agentes políticos no estén igualmente sujetos al efecto del priming.

Por otro lado, al igual que en el caso de la configuración de la agenda, el priming no depende exclusivamente del mensaje, sino también de la audiencia y su predisposición. El juego de interacciones que antes hemos mencionado y el hecho de que nos hallemos ante unos comicios de localidades relativamente pequeñas, cuya agenda pública de discusión está más o menos al alcance de todo ciudadano, hacen que la audiencia presente unas características distintas de las consideradas por Iyengar y Kinder (1987: 95) en su estudio. Si, para la perspectiva del agenda setting, la característica de la audiencia que parecía más relevante era el conocimiento previo y la implicación en la realidad política, y tenía más efecto entre aquellos con menos interés político, el priming actúa tanto sobre quienes sienten interés por los asuntos políticos como sobre quienes no.

\section{Metodología}

Para la realización del análisis, mayormente cualitativo, se ha optado por examinar la programación de las televisiones locales de ambos municipios, criban- 
do los programas que podían ser útiles para analizar los fenómenos señalados en el marco teórico. La primera selección fue de tipo temporal, decidiendo analizar la programación de los tres meses anteriores a la fecha de las elecciones: el 22 de mayo de 2011, incluyendo la campaña electoral en sí. Consideramos los dos meses y medio anteriores como periodo de precampaña, un concepto que ha ido alargándose si no perpetuándose en el tiempo en los últimos años, teniendo en cuenta que la vigilancia ejercida por la opinión pública y el resto de los medios de comunicación es menor que en el periodo oficial de campaña y que, durante esta, la mayor parte del electorado ha tomado ya una decisión de voto (Díez Nicolas y Semetko, 1995: 302, citado en Berrocal, 2003).

Posteriormente, se pasó a analizar el contenido de las parrillas para determinar cuáles de sus programas ofrecían mayores posibilidades de comprobar los efectos mencionados. Parecía claro que había que seleccionar los informativos diarios, con lo cual se hizo un barrido por los sumarios de estos espacios durante el margen temporal acotado, para ver si contenían piezas relacionadas con inmigración y/o su respuesta política a la misma. Se tomó la pieza noticiosa como unidad de análisis y, finalmente, se seleccionaron 21 de ellas para Badalona y 17 para L'Hospitalet. Pero, además, la propia dinámica electoral hace que programas que, en principio, no tienen una lógica informativa tan clara como un noticiero, caso de los magacines, adapten sus contenidos durante el periodo contemplado como campaña electoral. También, durante este espacio de tiempo, las televisiones tienden a hacer programas especiales, distintos de la pauta habitual, como entrevistas a los candidatos o debates. Aunque estos tres últimos se salen de la mencionada pauta, los hemos incluido en el análisis por ofrecer grandes posibilidades para el estudio cualitativo (adjetivación, ideas fuerza, etc.). Por tanto, y separando por municipios, nos hemos decantado por los espacios que detallamos a continuación.

\subsection{Badalona}

- El informativo Badalona Notícies (en el texto, utilizaremos las siglas BN), en antena de lunes a viernes a las 20 horas, con una duración algo inferior a los treinta minutos. La muestra analizada tuvo lugar entre el 9 y el 20 de mayo de 2011 y consta de 21 piezas: 12 se emitieron antes de la campaña electoral y 9, durante la misma, lo que supone un total de 37 minutos y 5 segundos seleccionados para el análisis, de los cuales 22 minutos y 3 segundos se emitieron antes de la campaña, y 15 minutos y 2 segundos, durante la misma.

- Análisis conjunto de las entrevistas a los candidatos al consistorio de Badalona con representación en los programas Sortida Nord (martes y jueves a las 20.30 horas, con redifusiones) - perfil más personal, pero que apunta algunas ideas políticas, de unos 15 minutos de duración-y Set Dies (viernes a las 21 horas, con redifusiones durante el fin de semana) — entrevistas políticas de alrededor de 10 minutos de duración insertadas dentro de bloques ágiles. 
- Debate electoral en el programa La Plaça de la Vila (50 minutos), de fecha 23 de marzo de 2011, con candidatos (en los casos de CiU, PP e ICVEUiA) y representantes (en los de ERC y PSC) de las formaciones del Ayuntamiento. Se trata de la última mesa redonda a cinco en Badalona antes de la campaña electoral, caracterizada por un gran número de debates en distintos medios. Este tipo de programas permite observar cómo los partidos contraponen las ideas de un modo más directo, cosa que en otros formatos no ocurre.

\subsection{L'Hospitalet}

- L'Hospitalet al dia (ediciones vespertina y de fin de semana. En el texto, utilizaremos las siglas L'HD), informativo diario en antena a las 20.30 horas, de apenas treinta minutos de duración. Se recoge una muestra de 17 piezas: 9 se emitieron antes de la campaña electoral y 8 durante la misma, lo que supone un total de 24 minutos y 55 segundos seleccionados para el análisis, de los cuales 16 minutos y 37 segundos se emitieron antes de la campaña, y 11 minutos y 18 segundos, durante la misma.

- Entrevistas a los cuatro candidatos municipales con representación en el consistorio de L'Hospitalet, incluidas como un apartado dentro del magacín de mediodía (con redifusiones) Districte 8 (en el texto, nos referiremos a él como D8), que tienen lugar en el periodo de campaña. La duración de cada una oscila entre los 25 y los 28 minutos.

\subsection{Características del análisis en función del tipo de programa}

Descontado el tiempo que se ha tardado en efectuar los barridos de los informativos diarios para la extracción de las piezas, el conjunto del visionado de los programas ha sido, por tanto, de algo más de 300 minutos. Algunos de los formatos no pueden ser subdivididos en piezas noticiosas y, además, se emiten fuera de la pauta habitual, con lo que resultan algo más difíciles de codificar y de comparar (en especial, las entrevistas, que tienen dinámicas muy diferentes en cada una de las televisiones locales), con lo que, en estos casos, se ha optado por condensar su análisis combinándolo con la extracción de ideas principales de los partidos en espacios noticiosos. Un ejemplo de ello se recoge en la tabla 6.

En el caso del análisis de las piezas de los informativos diarios, se han usado algunas pautas cuantitativas, como la medida de la duración porcentual de la pieza respecto al total del informativo o establecer qué posición ocupan en el sumario (si es que aparecen en este) y en el desarrollo del informativo. El análisis más técnico se completa con la mención a los recursos de imagen si fueran relevantes, además de observar qué tipo de noticias anteceden y suceden a las piezas mencionadas (se introduce la tabla 5 a modo de ejemplo paradigmático). La politización del discurso en su sentido más cualitativo queda determinada por las ideas principales que se aportan en cada pieza y por las declaraciones recogidas en la misma (ejemplos en tablas 4, 6, 7 y 9). 
Las entrevistas se prestan a un análisis más cualitativo, en cuanto interesa saber en qué orden son formuladas las preguntas por parte de los periodistas, así como qué ideas, problemas, ventajas, causas y consecuencias aparecen ligadas al fenómeno migratorio (seguridad, multiculturalidad, civismo, etc.). En una vertiente más cuantitativa, del tiempo total de la entrevista, se analiza cuánto se destina directa o indirectamente a inmigración y ligado a qué (ejemplificación en la tabla 8).

Por su parte, el debate con todos los candidatos en Badalona presenta, como hemos avanzado, una contraposición de ideas más directa y permite observar quién marca la pauta de los temas, que no es necesariamente el moderador. La primera presentación de ideas fuerza, las alusiones, en torno a qué temas hay consensos y en torno a cuáles no son los aspectos que nos interesan en este caso, más que la distribución de los tiempos, que es bastante similar para todas las fuerzas, aunque quizá algo mayor para las más votadas.

La elección de estos programas responde a un criterio de comparabilidad: formatos semejantes y horarios de emisión parecidos permiten observar el grado de paralelismo entre las prioridades periodísticas y las políticas en términos de agenda setting y fenómenos derivados. Existe más dificultad para la comparación entre las entrevistas de ambas localidades $\mathrm{y}$, de hecho, se han codificado de manera distinta, pero dan pie a hacerse una idea acerca de qué temas de los programas electorales priorizan los periodistas al preguntar a los candidatos y de cómo estos desarrollan su discurso, si lo hacen de igual modo que en los totales de las noticias o en los debates (cómo articulan sus ideas fuerza, en definitiva). En cambio, el análisis del informativo diario permite observar la continuidad, la priorización, el enmarcado y el tiempo dedicados a los discursos.

$\mathrm{Al}$ margen de la codificación habitual, cuando un espacio específico tiende a mostrar de una manera muy clara alguna de las pautas que queremos explicar, se usa una tabla a tal efecto. Por ejemplo, hemos reservado el uso de la tabla 5 para hablar específicamente de agenda setting en Badalona seleccionando dos jornadas (una antes y otra durante la campaña) que nos parecen reveladoras de la dinámica. Lo propio ocurre con la tabla 9, que explica el desarrollo de un informativo que selecciona un día concreto durante la campaña en L'Hospitalet para hablar exclusivamente de inmigración. Ya el hecho de que los propios servicios informativos opten por esa dinámica indica el calado del tema, pero, además, hemos querido analizar el contenido de manera detallada.

\section{Resultados}

\subsection{Badalona}

\subsubsection{Agenda setting $y$ priming}

La conclusión más clara que se extrae del análisis sobre Badalona es que Xavier García Albiol (PPC) es quien marca la agenda en este municipio, una función que le reconoce indirectamente el propio alcalde de la ciudad en ese momento, 
Jordi Serra (PSC), cuando señala que el hecho que diferencia a Badalona de otras ciudades de su entorno es que, teniendo los mismos problemas en cuestiones de inmigración, Albiol «hace años que se dedica a manipular la realidad y a hacer xenofobia» (Badalona Notícies, 17 de mayo de 2011, recogiendo el debate que tuvo lugar en el programa Ágora de TV3 — esto es, visible en toda Cataluña-) o cuando interpela a un presentador diciéndole "todavía no me ha preguntado usted por el PP» (entrevista en Set Dies, 25 de febrero de 2011).

El candidato del PP no solo prioriza la inmigración en la discusión pública sino que, además, consigue que tanto sus rivales como la televisión local enfaticen más esa relevancia, porque todos dicen estar en contra de la visión de Albiol acerca del asunto y permanecer unidos en esta cuestión. Juega, en definitiva, con lo que, en marketing político, se denomina teoría del desmarque minimo, que señala que cualesquiera que sean la campaña y las opciones elegidas, resulta indispensable que estas le concedan ventaja, al menos en un aspecto concreto al político; porque, de otro modo, no se diferenciaría de sus competidores (Maarek, 2009: 84). En términos de retórica, el desmarque mínimo se vincula con la inventio, que es la operación en la que se deciden los elementos de fondo sobre los que se elaborará el discurso y que, en última instancia, son los que poseen la mayor fuerza persuasiva (Pericot i Canaleta et al., 2007: 161). Al final, el discurso de García Albiol no es más que la continuidad del racismo de élite que se ha asentado con cierta facilidad en el PP, tal y como recoge Van Dijk respaldándose en el discurso del alcalde del mismo partido en El Ejido tras el brote xenófobo del año $2002^{2}$ y, a nivel estatal, en la aprobación de la Ley de Extranjería del mismo año, con los conservadores en el gobierno. Si España no dispone de un partido de ultraderecha es porque las diversas opciones de discurso antiextranjero han encontrado acomodo en el seno del Partido Popular (Van Dijk, 2003b: 28) y diversos actores, caso del que fuera recientemente candidato a la Generalitat de Catalunya, han mantenido más o menos vigente este tipo de discursos a lo largo de los últimos quince años. La campaña analizada no se encuentra temporalmente vinculada a los momentos de mayor apogeo de la consideración de la inmigración como un problema de España en los barómetros del CIS (por ejemplo, en abril de 2011, la consideraba así un $12 \%$ de los encuestados y, en mayo del mismo año, un $11,2 \%$ ), que ha ido cayendo desde 2010 y solo ha sufrido cierto repunte últimamente, debido a la crisis de refugiados. Sin embargo, la etiqueta de "problema» continúa latente.

La voluntad de Albiol de ser quien establece la agenda es clara, pero la actuación del resto de los candidatos favorece, de hecho, el discurso de este. Los efectos de priming y de framing derivados del agenda setting se acentúan, y la presentación de los espacios de la televisión local desempeñan un papel impor-

2. El asesinato de la joven Encarnación López a manos de un magrebí en la localidad almeriense de El Ejido desató una ola de violencia sin precedentes en la que vecinos armados con barras de hierro atacaron locales vinculados con comunidades inmigrantes. Hubo 22 heridos, pero no se registraron detenciones (El País, 7 de febrero de 2000). 
Tabla 4. Ideas que el resto de fuerzas políticas atribuyen al discurso del PPC de Badalona sobre inmigración

\begin{tabular}{|c|c|c|c|}
\hline PSC & CiU & ICV-EUiA & ERC \\
\hline $\begin{array}{l}\text { — Falta de patriotismo } \\
\text { local. } \\
\text { — Aumentar la conflic- } \\
\text { tividad entre barrios } \\
\text { como estrategia. } \\
\text { _ Una mentira repetida } \\
\text { muchas veces no es } \\
\text { una verdad. } \\
\text { _ Uso de Badalona } \\
\text { como laboratorio } \\
\text { electoral. } \\
\text { _ Incitación al odio y a } \\
\text { la xenofobia. } \\
\text { - Albiol como político } \\
\text { sin alma. } \\
\text { _ Estrategia de resulta- } \\
\text { dos mediáticos. }\end{array}$ & $\begin{array}{l}\text { - Imagen de Badalona } \\
\text { como polvorín. } \\
\text { — Creador de falsas } \\
\text { expectativas. } \\
\text { — Ofrece una imagen } \\
\text { de la ciudad como } \\
\text { gueto, que no es real. } \\
\text { - Discurso que divide. } \\
\text { - Pirómanos que luego } \\
\text { se ofrecen a apagar } \\
\text { el incendio. }\end{array}$ & $\begin{array}{l}\text { — Se transmite una } \\
\text { mala imagen de } \\
\text { la inmigración. } \\
\text { — Badalona no puede } \\
\text { ser conocida porque } \\
\text { un xenófobo gobierne } \\
\text { en ella. } \\
\text { - Ciudad a punto de } \\
\text { «hacer crac». }\end{array}$ & $\begin{array}{l}\text { - PP como ganador de } \\
\text { la batalla mediática. } \\
\text { - Cuatro candidatos } \\
\text { defienden la ciudad. } \\
\text { Otro dice que vivir en } \\
\text { ella es insoportable. } \\
\text { - Demagogia. } \\
\text { - Política hecha a golpe } \\
\text { de titular o de estó- } \\
\text { mago. }\end{array}$ \\
\hline
\end{tabular}

tante en ello. Es el diseño de ese frente común contra Albiol, muy personalizado además, lo que favorece el priming de la inmigración: se convierte en un asunto decisivo a la hora de postularse como referente por el cual valorar la actuación del gobierno al modo en que enuncian Scheufele y Tewksbury (2007). Los otros cuatro partidos con representación en el Ayuntamiento son inducidos por Albiol a ofrecer propuestas en materia migratoria, pero lo que hacen finalmente es atacar su discurso al respecto: deciden achacarle unos atributos negativos. El priming se da porque se prioriza la valoración del discurso antes que el propio fenómeno migratorio o las políticas que deberían hacerse en torno a él.

En definitiva, es la fuerza del discurso de uno y la unión en bloque de los otros contra él lo que genera el encuadre: la inmigración como uno de los primeros asuntos a considerar por parte de los votantes a la hora de evaluar la gestión pública de cara a los comicios, además de cumplirse lo que recogían Iyengar y Kinder en News that matters (1988): la intensificación del efecto del priming en una sola persona. El hecho de que prácticamente todas las noticias relativas a Albiol o las entrevistas concedidas por él lleven, velada o descarnadamente, una referencia a la inseguridad, fuertemente atribuida a cierto tipo de inmigración, hacen que el medio enfatice aún más el priming. Por lo demás, el formato periodístico del debate (en la última semana de campaña electoral, tuvieron lugar hasta cuatro debates a cinco e incluso un cara a cara entre Serra y Albiol) también ahonda en la confrontación de ideas.

Esta relevancia que se otorga al discurso del líder del PP local y su ensalzamiento indirecto como marcador de la agenda viene acompañado del posicionamiento que los informativos toman hacia su discurso y las reacciones ante el mismo. Una referencia indirecta al candidato en el pregón de las fiestas 
Tabla 5. Ejemplo de agenda setting de la candidatura popular de Badalona. Tiempos y posición

\begin{tabular}{|c|c|c|c|c|c|}
\hline Fecha & Piezas analizadas & $\begin{array}{l}\text { Posición en sumario } \\
\text { e informativo }\end{array}$ & $\begin{array}{c}\text { Duración de } \\
\text { cada pieza }\end{array}$ & $\begin{array}{l}\text { Porcentaje de } \\
\text { duración del bloque } \\
\text { de inmigración } \\
\text { respecto al total del } \\
\text { informativo }\end{array}$ & $\begin{array}{l}\text { Porcentaje de } \\
\text { duración del bloque } \\
\text { de inmigración } \\
\text { sin contabilizar } \\
\text { deportes y tiempo }\end{array}$ \\
\hline \multirow{3}{*}{$\begin{array}{l}\text { 2/3/2011 } \\
\text { (antes de } \\
\text { la campaña) }\end{array}$} & $\begin{array}{l}\text { 1. Albiol: mano dura } \\
\text { contra inmigrantes } \\
\text { incívicos que no se } \\
\text { integran (mención } \\
\text { expresa a gitanos } \\
\text { rumanos). }\end{array}$ & $\begin{array}{l}\text { Abre sumario, } 2 .^{a} \\
\text { posición en el infor- } \\
\text { mativo. }\end{array}$ & $2 \min 9 s$ & \multirow{3}{*}{$13,8 \%$} & \multirow{3}{*}{$23,3 \%$} \\
\hline & $\begin{array}{l}\text { 2. Reacción de } \\
\text { Serra. }\end{array}$ & $\begin{array}{l}\text { No en el sumario, } \\
\text { 3. a posición en el } \\
\text { informativo. }\end{array}$ & $44 \mathrm{~s}$ & & \\
\hline & $\begin{array}{l}\text { 3. Reacción de } \\
\text { Unescocat. }\end{array}$ & $\begin{array}{l}\text { No en el sumario, } \\
4 .^{a} \text { posición en } \\
\text { informativo. }\end{array}$ & $50 \mathrm{~s}$ & & \\
\hline \multirow{2}{*}{$\begin{array}{l}\text { 16/5/2011 } \\
\text { (durante } \\
\text { la campaña) }\end{array}$} & $\begin{array}{l}\text { 1. Mitin de Albiol } \\
\text { muy enfocado } \\
\text { hacia la } \\
\text { inmigración. }\end{array}$ & $\begin{array}{l}\text { No en el sumario, } \\
\text { abre bloque electoral, } \\
\text { 2. }^{\text {a }} \text { posición en el } \\
\text { informativo. }\end{array}$ & $2 \min 10 s$ & \multirow{2}{*}{$13,5 \%$} & \multirow{2}{*}{$21,7 \%^{*}$} \\
\hline & $\begin{array}{l}\text { 2. Reacción } \\
\text { de Serra. }\end{array}$ & $\begin{array}{l}\text { No en el sumario, } \\
\text { 2. a posición en } \\
\text { bloque electoral, } \\
\text { 3. a en el informativo. }\end{array}$ & $1 \mathrm{~min} 58 \mathrm{~s}$ & & \\
\hline
\end{tabular}

* $\mathrm{Sin}$ contabilizar ligeras menciones que hacen candidatos de CiU y ICV-EUiA.

locales, las declaraciones a posteriori del alcalde Serra cuando, en un mitin de precampaña, Albiol pide «mano dura para algunos inmigrantes incívicos que no se integran» (BN, 2 de marzo de 2011) —esto es, una apelación de «sentido común» amparándose en la «legalidad» y una construcción clara de la otredad (Van Dijk, 2003b: 41)—, o manifestaciones ad hoc, fuera de actos políticos, de Serra tras mítines de Albiol en campaña son buena muestra de ello. Por añadidura, las declaraciones reactivas respecto a las de Albiol en cuanto a seguridad, inmigración o civismo no son patrimonio exclusivo de los políticos: organizaciones como Unescocat también se posicionan sobre ellas y aparecen en las noticias tras el discurso del popular.

Como vemos, hay días en los que el porcentaje de información relativa a inmigración copa una parte importante del tiempo del noticiero, sobre todo si eliminamos bloques en los que este tipo de piezas no tiene cabida, como los deportes o el tiempo. Quien posteriormente se convirtiera en alcalde de Badalona marca la pauta y, en cierto modo, induce tanto a sus contrincantes como a otros agentes sociales a seguir la estela trazada por él. Si bien, como ya hemos señalado, la televisión de Badalona trata de equilibrar las barreras de tiempos otorgados por la Ley Electoral a cada partido empezando cada día el bloque de las formaciones políticas con una distinta, el hecho de que Albiol 
introduzca la temática fuerza a los periodistas a posicionar las piezas detrás de las del candidato popular, como reacción a lo dicho por este.

\subsubsection{Framing y cualidades de los discursos}

\subsubsection{Politicas públicas}

Fuera del periodo electoral, los partidos en el gobierno en aquel momento (PSC, CiU y ERC) tienen cierta ventaja en la pauta del «qué pensar» acerca de la inmigración, gracias a que son los responsables de las políticas públicas y a que el modo en que estas son presentadas en los informativos puede fomentar unas u otras actitudes. Si nos acogemos a la definición de framing de Shoemaker y Reese (1996), que subrayan el hecho de que la presentación de las noticias está muy relacionada con los esquemas mentales preexistentes en la audiencia, vemos que el propio Ayuntamiento trabaja en este sentido, con una "campaña antirrumores" (BN, 18 de marzo de 2011) que, a su vez, es presentada en el informativo con una pieza de tres sobre un total de 27 minutos (incluyendo los deportes y el tiempo), con lo que podemos decir que la duración es considerable. Antes de la campaña, el reflejo de las políticas públicas sobre inmigración en el informativo es notorio, las piezas son largas y aparecen encabezando el sumario. Aquellas referidas a jóvenes y a niños inmigrantes son muy descriptivas y se asocian a atributos positivos, como la inserción sociolaboral, el hecho de que los jóvenes aparezcan hablando catalán, etc. (BN, 24 de marzo de 2011).

Otras noticias, como la firma de un plan piloto de inmigración, se sitúan en la zona intermedia entre los aspectos positivos y los negativos. Tiene un posicionamiento similar al expresado más arriba, pero las propias ideas del espectador pueden enmarcar estas intervenciones públicas, ya sea como una buena inversión, ya sea como un gasto innecesario. En todo caso, el fenómeno aparece como algo que demanda tratamiento y gestión: se utilizan expresiones como "trabajo conjunto de administraciones», "esfuerzo», «acogida», y se señala que las actividades serán de tipo cultural y deportivo, pero incidiéndose también en los «derechos y deberes» de los recién llegados. Además, volviendo a lo dicho anteriormente, en el acto de presentación, esta nueva política pública también se aprovecha para afear a "otros que hacen xenofobia» (BN, 8 de marzo de 2011). El enmarcado a contrario del discurso y la sombra del candidato Albiol son, pues, constantes.

\subsubsection{Aspectos negativos del fenómeno migratorio}

El encuadre de los informativos da a entender que, aunque la inmigración acarrea dificultades, generalmente, estas pueden solucionarse o mitigarse. Cuando se habla de fenómenos como el «mercado de la miseria» (BN, 22 de febrero de 2011) —en sí misma, una denominación con una evidente carga peyorativa, a la que se añaden imágenes que dejan a las claras los rasgos fenotípicos de los implicados-o del absentismo escolar (BN, 28 de febrero de 2011) —aquí la mención a las nacionalidades no es explícita-, se alude a que bien los cuerpos policiales, bien regulaciones específicas servirán para gestionarlos. Si se incide 
en la intervención institucional, la información aparece presentada, si no en positivo, sí como algo solucionable y ordenado en una posición intermedia de los informativos, con lo que se suaviza una posible interpretación muy negativa. En cambio, si bien las noticias de sucesos no reciben una cobertura particularmente larga y rara vez se hace mención explícita de nacionalidades o se identifican grupos étnicos, sí están bien posicionadas. Otra peculiaridad que hemos detectado es el uso de imágenes de recurso en las que sí aparecen inmigrantes en informaciones relativas a educación y a desempleo.

Una referencia aparte merece el caso de los gitanos rumanos dentro de la globalidad del discurso migratorio. Este tema ya había sido debatido en otros países de Europa, centrándose en este grupo étnico y con fuertes controversias, especialmente en Francia e Italia. La mención a la «mano dura contra los incívicos que no se integran» marcó mucho la precampaña y la campaña posteriores. En ese mismo acto del PPC, se ejemplifica el incivismo personificándolo en «determinados individuos gitanos rumanos», presentándolo no como opinión subjetiva, sino como un hecho y, por ende, como parte del régimen de verdades establecidas (Van Dijk, 2003b: 39). Además, las afirmaciones del futuro alcalde casaban muy bien con respuestas espontáneas recogidas en encuestas como la titulada Actitudes hacia la inmigración (IV), de septiembre-octubre de 2010, realizada por el Centro de Investigaciones Sociológicas (la inmediatamente anterior a los comicios estudiados), donde los encuestados situaban a los rumanos como el segundo grupo en el cual pensaban cuando se hablaba de inmigración (13,8\%, poco menos de un punto por debajo del primer grupo en el que se pensaba: marroquíes y otros norteafricanos). El rechazo a esta etnia también se enmarca dentro de lo que Cea D’Ancona y Valles Martínez (2010: 271) consideran xenofobias y xenofilias específicas según la relación percibida con conductas delicitivas y de violencia, y en las cuales, señalan, tiene fuerte influencia la exposición de los hechos aludiendo a la nacionalidad del reo.

Un par de detalles en los informativos analizados señalan a este grupo étnico: primeramente, una pieza que alude al archivo de una querella presentada por SOS Racismo contra García Albiol por incitar a la violencia contra los romaníes —en las imágenes que utiliza la noticia, se ve claramente un folleto repartido por el candidato, que recoge una instantánea de una pintada que dice «No queremos rumanos»- (BN, 9 de marzo de 2011). El otro es una denuncia del propio PPC, recogida por el informativo, acerca de robos perpetrados en diversos comercios de la zona alta del barrio de Llefià. Por el formato que se da a la noticia, se trata, probablemente, de una nota de prensa enviada por el propio partido, ya que esta alude a que los presuntos delincuentes son gitanos rumanos. Se acompaña de declaraciones de García Albiol señalando el miedo de los vecinos a denunciar los hechos por las amenazas de los propios ladrones (BN, 19 de abril de 2011).

\subsubsection{Discurso sobre migración: contenido}

Como se puede observar en la tabla 6 , el mayor número de valoraciones del fenómeno migratorio, en su mayoría negativas, corresponde al PPC, que trata 
Tabla 6. Ideas fuerza de los partidos de Badalona sobre inmigración

PSC

- Cohesión, identidad y autoestima.

- Proyectos estratégicos que hacen de Badalona una sola ciudad.

- Trabajo conjunto de las administraciones.

- Badalona ha de posicionarse como referente positivo.

- Situación no muy distinta a la de otros municipios de Cataluña.

\section{PP}

- Dos Badalonas.

- Mano dura contra los inmigrantes incívicos que solo han venido a delinquir. Los que delinquen son minoría.

- Impulso a la policía de barrio.

- No dar ayudas sociales a incívicos.

- Presión policial.

— «El que quiera ser uno de nosotros, será uno de nosotros.»

- Relación con inseguridad.

- Mención directa a gitanos rumanos.

- Hay dos Badalonas, necesidad de ser una sola.

- Personas que venden sus casas y deciden irse a otras partes de la ciudad o fuera de Badalona por el clima existente en los barrios.

— Altos índices de exclusión social en 13 barrios.

\section{CiU}

- Existencia de un buen plan de acogida.

- Badalona no es un gueto.

- El representante político como oferente de información, que no incentiva los rumores.

- Posibles problemas de aplicación de la justicia.

\section{ICV-EUiA}

- La inmigración no es un problema, lo es la crisis.

- Ciudad a punto de «hacer crac».

\section{ERC}

- Espacio de convivencia, cohesión social y civismo.

- Aumento de servicios sociales.

de paliar la generalización con algunos matices: "Quien quiera ser uno de nosotros, será uno de nosotros» (BN, 16 de mayo de 2011) — dejando entrada a los valores de otredad, tan típicos de estos discursos - o al indicar que los inmigrantes incívicos «no son todos» (cara a cara recogido en BN, 9 de mayo de 2011). Por ligar estas características a lo señalado antes sobre el priming, hay que hacer un apunte acerca de la apertura de la campaña electoral: en la pieza dedicada al PPC, se observa a Albiol pegando un cartel en el que aparece él con un esparadrapo en la boca y a punto de quitárselo, dando a entender 
que el discurso que él defiende es mayoritario en Badalona, pero que existe presión social en contra y una suerte de espiral del silencio al modo enunciado por Noëlle-Neumann (1974) (BN, 6 de mayo de 2011).

La noción de «las dos Badalonas», que Albiol utiliza pero que sus contrincantes también recogen, aunque sea para contestarle, tiene bastante fuerza persuasiva y actúa como base del discurso popular. Al final, es el propio discurso el que articula la realidad gracias a imágenes mentales más fuertes.

En fin, la existencia de un actor con una influencia muy fuerte en el agenda setting hace que los mecanismos de framing y priming derivados de ella sean también muy intensos. Los tiempos mediáticos, los discursos poco neutrales - la inmigración como tema de posición y no de valencia-, así como el hecho de que las otras fuerzas políticas y los agentes sociales intervengan, hacen que, en Badalona, la politización de la inmigración se intensifique. Las propias dinámicas televisivas de campaña (muchos debates y un cara a cara) no hacen sino reforzar el fenómeno.

\subsection{L'Hospitalet}

\subsubsection{Agenda setting $y$ priming}

A diferencia de Badalona, en L'Hospitalet, el discurso en torno a la inmigración es coral, y si bien todos los partidos tienen una posición al respecto, no hay ningún candidato que parezca despuntar. Además, se observa que los medios de comunicación dan mucho más la pauta, introduciendo el tema de la inmigración cuando preguntan directamente a los candidatos en las entrevistas. Es decir, si bien todos los partidos tienen propuestas sobre el tema, las ideas en torno a las cuales se enmarca el fenómeno y sus posibles implicaciones positivas o negativas no definen la agenda de un modo tan destacado. En suma, se puede llegar a deducir que los partidos quieren mantener los asuntos relacionados con la inmigración en un perfil más bien bajo durante la campaña, y que no son ellos sino la televisión local la que considera que hay que darles más relieve.

El hecho más destacable es que todas las fuerzas políticas abrazan la idea de «derechos y deberes», implícita o explícitamente, en sus intervenciones. El gobierno local, entonces con mayoría absoluta del PSC, insiste en la existencia de las ordenanzas de civismo. Se quiere dar a la inmigración un cariz casi técnico, de mera gestión, desproblematizándolo y, si se quiere, despolitizándolo, justo al contrario que en Badalona. En general, los informativos también divulgan la existencia de ciertos procedimientos asociados con los inmigrantes (reagrupamiento familiar, empadronamiento) y el deseo de vincularlos al respeto de una serie de normas. En fin, la inmigración aparece como un fenómeno a gestionar mediante el uso de ciertas herramientas.

En cuanto al priming, no son los partidos los que, en primera instancia, dan notoriedad a este fenómeno como modo de evaluar la gestión política, o al menos no es así durante la campaña. Es más bien la labor periodística la que intenta que los candidatos se posicionen, aunque, como hemos avanzado, lo 
Tabla 7. La inmigración como fenómeno a gestionar. Herramientas y problemas. Partidos con representación en L'Hospitalet

\begin{tabular}{|c|c|c|c|}
\hline PSC & PP & CiU & ICV-EuiA \\
\hline $\begin{array}{l}\text { - Necesidad de civismo } \\
\text { y construcción de } \\
\text { «espacio amable». } \\
\text { Pacto local por la con- } \\
\text { vivencia. } \\
\text { — Mediación en conflic- } \\
\text { tos vecinales. Necesi- } \\
\text { dad de diálogo. } \\
\text { - Incremento de dota- } \\
\text { ciones policiales. } \\
\text { - Condicionar el rea- } \\
\text { grupamiento y el } \\
\text { empadronamiento } \\
\text { a las ordenanzas de } \\
\text { incivismo. Multas por } \\
\text { sobreocupación de } \\
\text { vivienda. } \\
\text { — Mayorcooperación } \\
\text { ewntre la Generalitat y } \\
\text { el Ayuntamiento. } \\
\text { - Mismos deberes y } \\
\text { obligaciones. } \\
\text { — Lucha contra el } \\
\text { incivismo «venga de } \\
\text { donde venga» (disua- } \\
\text { sión, sanciones). }\end{array}$ & $\begin{array}{l}\text { - Rechazo a la } \\
\text { multiculturalidad: } \\
\text { no hay por qué } \\
\text { aceptar lo extranjero } \\
\text { que no casa con las } \\
\text { libertades (burka). } \\
\text { - Se arrogan unos } \\
\text { derechos que no } \\
\text { tienen en sus países } \\
\text { de origen. } \\
\text { - Deberes como con- } \\
\text { traprestación. } \\
\text { - Necesidad de expul- } \\
\text { sar a los inmigrantes } \\
\text { incívicos. Servicios } \\
\text { a la comunidad para } \\
\text { aquellos incívicos de } \\
\text { origen español. } \\
\text { - Control a las bandas } \\
\text { latinas. } \\
\text { - Actuación contunden- } \\
\text { te contra incívicos y } \\
\text { delincuentes. } \\
\text { - Enfermedades: nor- } \\
\text { mal en un mundo } \\
\text { globalizado. }\end{array}$ & $\begin{array}{l}\text { — Fomento de la } \\
\text { multiculturalidad. } \\
\text { — Que se respeten } \\
\text { las ordenanzas de } \\
\text { civismo. } \\
\text { — En temas de civismo, } \\
\text { las normas no están } \\
\text { claras. De ahí deriva } \\
\text { el alto absentismo } \\
\text { laboral de la Guardia } \\
\text { Urbana. } \\
\text { — Mayor presencia } \\
\text { policial. } \\
\text { — Problema de falta de } \\
\text { cohesión social. } \\
\text { - Asociación del reagru- } \\
\text { pamiento familiar } \\
\text { a informes. } \\
\text { - Mucha permisividad } \\
\text { del PSC en la Gene- } \\
\text { ralitat. No se hacía } \\
\text { cumplir la ley y se } \\
\text { facilitaban «papeles } \\
\text { para todos». }\end{array}$ & $\begin{array}{l}\text { - Ciudad de acogida y } \\
\text { respeto a la diferencia. } \\
\text { — Ciudad diversa, en la } \\
\text { que se persiga a los } \\
\text { incívicos y no a las } \\
\text { personas. } \\
\text { - Petición de derechos y } \\
\text { deresponsabilidades. } \\
\text { Remisión a las orde- } \\
\text { nanzas. } \\
\text { - Cambio en el enfoque } \\
\text { de la inmigración: no } \\
\text { tratar el tema como } \\
\text { mera competencia por } \\
\text { recursos. }\end{array}$ \\
\hline
\end{tabular}

hacen en torno a unas coordenadas muy parecidas en el caso de aquellas formaciones con representación en el Ayuntamiento hasta ese momento. Quizá, como señalaremos en el framing, el más rotundo en este sentido es el Partido Popular, aunque CiU, con la figura de Felip Puig — en aquel momento conseller de Interior de la Generalitat, que acude a un mitin en la localidad-, no le va a la zaga. Formaciones menores, como PxC, abordan el discurso de modo muy distinto, pero su presencia en la programación es residual.

Dicho esto, la inmigración cobra cierta relevancia antes de la campaña - ya hemos señalado que el perfil desciende ligeramente durante la misma, al menos por parte de las distintas formaciones - gracias a las políticas públicas y a las informaciones de sucesos o por la intervención de otros agentes sociales. Un tema interesante es el de los pisos sobreocupados (L'HD Vespre, 12 y 26 de abril de 2011), que consigue buenos posicionamientos en el sumario y durante el informativo (lo abre en ambos casos), con piezas de entre dos y tres minutos de duración. Esta política en concreto sirve para diferenciar las posturas, especialmente entre PSC — que incide en que las multas por sobreocupación son elevadas y en que ha habido un descenso en su número gracias a ello - 
Tabla 8. L' Hospitalet. Entrevistas a los candidatos en Districte 8

\begin{tabular}{lllll}
\hline & PSC & PP & CiU & ICV-EuiA \\
\hline $\begin{array}{l}\text { Ideas principales } \\
\text { sobre inmigración }\end{array}$ & $\begin{array}{l}\text { Seguridad. } \\
\text { Civismo. }\end{array}$ & $\begin{array}{l}\text { Civismo. } \\
\text { Multiculturalidad } \\
\text { (desarrollado). }\end{array}$ & $\begin{array}{l}\text { Seguridad. } \\
\text { Civismo. } \\
\text { Enfermedades. } \\
\text { Bandas latinas. } \\
\text { (mencionado). }\end{array}$ & Seguridad. \\
& & $37,46 \%$ & $24,67 \%$ & $19,25 \%$ \\
$\begin{array}{l}\text { Porcentaje de tiempo } \\
\text { destinado a ideas } \\
\text { vinculadas con inmigración }\end{array}$ & $28,22 \%$ & & & \\
\hline
\end{tabular}

y $\mathrm{CiU}$ - que señala que los esfuerzos en la materia son insuficientes-. El hecho de que aparezca el testimonio personal de una vecina afectada por un denominado "piso patera» sirve como particularización del problema y como manera de hacerlo relevante, también porque es una noticia a la que se otorga continuidad.

La misma continuidad recibe el surgimiento de la Plataforma contra el Fascismo y el Racismo en L'Hospitalet (L'HD Vespre, 14 y 30 de abril), que da a entender que la politización y el encuadre no tienen porqué ser solo cosa de los partidos. En la misma línea están las noticias protagonizadas por el Centro de Información al Trabajador Extranjero de CCOO (CITE) (L'HD Vespre, 20 de abril) o la petición de la Asociación Árabe para que los inmigrantes con derecho a voto lo ejerzan (L'HD Vespre, 30 de abril). En suma, el priming en los informativos no es en absoluto tan intenso como en Badalona. De hecho, en campaña, es más bien bajo y está ejercido por multitud de agentes antes que por los partidos. Esa escasez se compensa con las entrevistas individuales a los candidatos, como se observa en la tabla inferior. El tiempo destinado a temas implícita o explícitamente relacionados con inmigración es relevante, sobre todo en el caso del PP.

\subsubsection{Framing y cualidades de los discursos}

\subsubsection{El debate nominalista: ¿inseguridad o incivismo?}

La idea común de derechos y deberes, así como de «tolerancia cero con el incivismo» es la que enmarca toda la agenda y en la que todos los partidos están de acuerdo. De entre las formaciones con representación, es el PSC, por ser el gobernante, y de manos de la alcaldesa Núria Marín, el que marca el punto de partida acerca de cómo juzgar actitudes incívicas o de inseguridad. De hecho, la alcaldesa contrapone estas dos palabras, señalando que lo que en un primer momento es considerado por algunos vecinos como problemas de inseguridad, "cuando se habla tranquilamente», se ve que se trata de incivismo, esto es, que estaríamos más bien ante un problema de matiz (Districte 8, 12 de mayo de 2011). Por su parte, Meritxell Borràs, candidata de CiU, discrepa con este planteamiento, respondiendo que la gente no dice que existen problemas de 
Tabla 9. Propuestas electorales sobre inmigración en L'Hospitalet (L'Hospitalet al dia, 14 de mayo de 2011)

\begin{tabular}{|c|c|c|}
\hline PSC & PP & $\mathrm{CiU}$ \\
\hline $\begin{array}{l}\text { - Demanda de mayor ayuda } \\
\text { de la Generalitat para las } \\
\text { necesidades de migrados. } \\
\text { - Inserción en catalán. } \\
\text { - Transmisión de la lengua } \\
\text { de origen. } \\
\text { - Cooperación internacional. }\end{array}$ & $\begin{array}{l}\text { - Programas de acogida } \\
\text { MENA y colectivos vulne- } \\
\text { rables. } \\
\text { - Exigencia de empadro- } \\
\text { namiento, así la policía } \\
\text { detectará la inmigración } \\
\text { ilegal mediante el censo. } \\
\text { - Revocación de los per- } \\
\text { misos de residencia y de } \\
\text { trabajo a los incívicos. }\end{array}$ & $\begin{array}{l}\text { - Coordinación entre la } \\
\text { Generalitat y el Ayun- } \\
\text { tamiento para políticas } \\
\text { sociales. } \\
\text { - Padrón que represente la } \\
\text { realidad del municipio. } \\
\text { - Lucha contra la contrata- } \\
\text { ción ilegal. } \\
\text { - lgualdad en el acceso a los } \\
\text { servicios públicos. }\end{array}$ \\
\hline ICV-EUiA & ERC & Ciutadans \\
\hline $\begin{array}{l}\text { - Pacto local de convivencia } \\
\text { y ciudadanía. } \\
\text { - Proyecto de deporte para } \\
\text { jóvenes inmigrantes. } \\
\text { - Reequilibrio en las aulas. }\end{array}$ & $\begin{array}{l}\text { - Inserción laboral y forma- } \\
\text { ción sobre todo de las } \\
\text { mujeres inmigrantes. } \\
\text { - Existencia de mediadores } \\
\text { sanitarios. } \\
\text { - Garantía de aprendizaje } \\
\text { del catalán. }\end{array}$ & $\begin{array}{l}\text { - Defensa del voto inmi- } \\
\text { grante. } \\
\text { - Uso de mediadores cultura- } \\
\text { les en conflictos vecinales. } \\
\text { - Revisión de las ordenanzas } \\
\text { sobre la convivencia. }\end{array}$ \\
\hline
\end{tabular}

Común para todas las formaciones: cohesión social, que los recién llegados formen parte del tejido asociativo, asesoramiento en derechos y deberes y evitación de guetos.

inseguridad por capricho (D8, 10 de mayo de 2011). En todo caso, todos los partidos coinciden en la existencia de instrumentos válidos para reconducir estos problemas si es que son provocados por extranjeros. Un buen ejemplo son las sanciones por los pisos sobreocupados arriba mencionadas. De entre las intervenciones de $\mathrm{CiU}$, hay que reseñar la de Felip Puig, que, en un mitin, no duda en criticar las consecuencias del "papeles para todos» del anterior ejecutivo de la Generalitat, comandado por el PSC (L'HD Vespre, 8 de mayo de 2011).

A partir de estas dos posturas más o menos centrales (ambas formaciones han presentado mociones y propuestas en las que se vincula el castigo al incivismo con un trámite; por ejemplo: la denegación del reagrupamiento familiar), emana el discurso de los otros partidos. El candidato del PP tiende a presentar ambas ideas, inseguridad e incivismo, como relacionadas. Su discurso no parece especialmente virulento, pero es tajante cuando es preguntado por fenómenos como las bandas latinas (es el único candidato al que se le pregunta) e introduce motu proprio el tema de las enfermedades (D8, 11 de mayo de 2011). El otro lado de la balanza lo representa el candidato de ICV- EUiA, quien, a la vez que se suma a la necesidad de respetar las ordenanzas, también advierte de un riesgo de «simplificación» del discurso migratorio, e incluso llega a acusar al resto de formaciones de «silencio cómplice» hacia discursos como el de $\mathrm{PxC}$ - centrado en la inseguridad y en "primero, los de casa»— (D8, 9 de mayo de 2011). 
Para hacernos una idea más aproximada sobre cómo se aborda el tema en las entrevistas, hemos medido el porcentaje de tiempo de las conversaciones con cada candidato que está asociado a inmigración y a qué ideas se vincula implícita o explícitamente.

\subsubsection{Aspectos negativos del fenómeno migratorio}

Ya hemos dicho que la propia dinámica de los medios pone de relieve la inmigración, pues los discursos de los partidos parecen algo encorsetados. Antes del bloque electoral del informativo del 14 de mayo de 2011, la televisión local recoge gráficamente las principales propuestas de cada formación. En la tabla 9 se muestran en negrita las asociaciones de ideas más destacadas.

Las noticias de sucesos que tienen a inmigrantes como protagonistas no parecen presentar una carga peyorativa reseñable a priori, pero sí alusiones a su «nacionalidad extranjera» (L'HD Vespre, 10 de mayo de 2011), lo cual ya induce a sesgo. Se incide en que las ideas expuestas anteriormente son gestionables de modo técnico y, de hecho, la pieza dedicada al Plan de Convivencia aprobado por el Gobierno autonómico tiene un buen posicionamiento en el informativo y una duración intermedia (L'HD Vespre, 16 de marzo de 2011), a pesar de los posibles inconvenientes: el partido gobernante defiende las medidas tomadas, y la oposición — quizá con la excepción de ICV- EUiA, que trata de vincular las acusaciones a la inmigración al miedo a la crisis - cree que esas medidas son buenas pero insuficientes. El recurso a la legislación, a los protocolos, a las ordenanzas, etc. es un modo muy socorrido de legitimación del racismo de élite, precisamente por la tranquilidad que pareciera aportar que ciertas acciones o resoluciones (en el caso que nos ocupa, las sanciones por pisos sobreocupados o las denegaciones de reagrupamiento) se hayan llevado a cabo conforme a la legalidad vigente (Van Dijk, 2003b: 39).

\subsubsection{La diferencia en los formatos}

Si en Badalona teníamos un marcador de la agenda claro, no es el caso de L'Hospitalet. El modo en el que la televisión local aborda el tema - y el modo en el que los agentes sociales actúan- parece más influyente, porque la mayoría de los partidos se mueven en unas coordenadas no excesivamente diferentes entre sí. También hay que considerar que los formatos importan al analizar la politización del mensaje. Las entrevistas en L'Hospitalet son más extensas y centradas en el programa electoral. Los periodistas, con el orden en el que preguntan, otorgan más o menos importancia al asunto. Sin embargo, en este municipio, solo hay un debate entre candidatos recogido por la televisión local con algunas imágenes, pero no retransmitido íntegramente, con lo cual también es más difícil contraponer las ideas.

\section{Discusión y conclusiones}

No solo en estas dos localidades, sino en cualquier otro lugar, es prácticamente inevitable concluir que la inmigración es un fenómeno crecientemente politi- 
zado. Y no solo por la intervención de los partidos políticos, sino también por la de otros agentes sociales o por la de los propios medios de comunicación y el cariz dado por ellos al asunto. Si bien cabe esperar que los mecanismos politizadores sean los mismos para todo fenómeno susceptible de formar parte de la discusión pública, hemos querido averiguar, en el caso del fenómeno migratorio, qué actores los usan más y, sobre todo, quién pauta los tiempos y cuál es su lenguaje.

La principal particularidad de Badalona es la aparición de un marcador destacado de la agenda y de los tiempos y que la polémica se da en dos niveles. Uno corresponde a la forma: el candidato del PP sugiere la apertura de un debate, se esté de acuerdo o no con sus términos, y la acción de abrirlo ya es percibida por partidos y otros agentes sociales como algo intrínsecamente perjudicial. El otro nivel del debate se sitúa en el fondo: la discusión acerca de posibles políticas de integración de recién llegados, por ejemplo, que quedan ocultadas por el énfasis en la forma.

Sin quererlo sus rivales, una acción unitaria frente al discurso de García Albiol ensalza aún más su iniciativa o su liderazgo acerca de las consideraciones que puedan tener lugar sobre las políticas hechas o por hacer en temas de inmigración. De esta manera, se desmarca de un perfil bajo y más bien conciliador de los demás candidatos (recordemos que, de las otras cuatro fuerzas que no son el PPC, tres gobernaban el Consistorio en ese momento) y, además, la carga de sus palabras y la fuerza de ciertas expresiones como «las dos Badalonas» —otredad — o "barrios en situación explosiva» no parecen dejar a sus contrincantes otra opción que la de reaccionar. Pero lo hacen al discurso, sin apenas ofrecer propuestas de gestión más allá de recalcar lo que ya se ha hecho. En suma: tenemos a un candidato que, efectivamente, politiza el discurso migratorio midiendo los tiempos y jugando con gran efectividad, tanto con su propio desmarque — en el modo señalado por Maarek (2009) — como con el hecho de obligar al resto de candidatos a posicionarse ante sus afirmaciones. Añadámosle a ello la intensa confrontación de opiniones en un gran número de debates. La teoría del agenda setting establecida por McCombs y Shaw, así como su principal derivación (el priming), desarrollada especialmente por Iyengar y Kinder, se cumplen estrictamente aquí: la inmigración como tema prioritario para decantar el voto, además de una fuerte vinculación del fenómeno - o de lo que se haría con él— con la persona de Albiol.

El modo en el que se lleva a cabo el debate en el caso de L'Hospitalet es muy otro. De entre los candidatos municipales, nadie marca la agenda de una manera tan patente como en Badalona. Todavía prevalece una especie de consenso tácito para mantener la cuestión migratoria fuera de un discurso de tono elevado por las consecuencias que esto pudiera acarrear, esto es: la huida de una politización excesiva. En L'Hospitalet, no hay tanta preocupación por el peligro del discurso sobre inmigración como por debatir cuáles son las herramientas más eficaces en caso de que esta tenga consecuencias poco deseables. Se quiere ofrecer un discurso cuasitécnico, aséptico, tranquilizador. Sin embargo, no desaparece esa percepción de la inmigración como, en el fondo, un pro- 
blema, y es que los mensajes que inciden en la necesidad de destinar mayores recursos a la inmigración, aunque no sea para su «control», sino tan solo para su «integración», tampoco ayudan a reducir la xenofobia (Cea D’Ancona y Valles Martínez, 2010: 482). Es por ello que prácticamente todas las formaciones políticas se aferran a unos consensos mínimos relativos a «derechos y deberes" y a ordenanzas de civismo - durante la legislatura se aprueban varias, presentadas también por diferentes grupos políticos- y, a partir de ahí, cada formación varía ligeramente su enfoque. Mientras que el PP se muestra más contundente - aunque también es la formación a la que más se le pregunta al respecto, incidiendo en fenómenos como las bandas latinas-, ICV-EUiA sí alude al posible peligro de una radicalización del discurso, pero no tanto del político, sino de una especie de silencio aquiescente con un discurso xenófobo que existiría en la calle.

Con todo, en L'Hospitalet, los desmarques no son muy acusados. Las divergencias en los posicionamientos surgen más bien acerca de cómo enmarca la campaña electoral el medio de comunicación local que hemos analizado: igual que antes de la misma, sí que hay cierta incidencia en informaciones intrínsecamente relacionadas con la inmigración - los pisos patera (nominación que ya tiene una carga peyorativa y que es asumida acríticamente por el medio) aparecen como información de continuidad—, durante la misma, los partidos tratan de mantener el perfil del tema bajo. Así pues, es el medio el que lo realza, sobre todo en las entrevistas a los candidatos. Esto se observa en la formulación de las preguntas, en la alusión a las encuestas de percepción ciudadana, etc. Por lo tanto, la politización —en este caso, muy enfocada a inducir a los candidatos a posicionarse - aparece aquí más ejercida por los periodistas que por los partidos. Aunque los segundos sí juegan con ligeras diferencias en sus discursos, lo hacen muy lejos de querer otorgar a la inmigración una primacía como tema decisivo desde el punto de vista electoral. También hay que señalar que solo existe un debate con todos los candidatos y que ni siquiera se retransmite - fuera de una pequeña pieza noticiosa en el informativo, de menos de dos minutos de duración-en la televisión local.

En fin, en el caso de Badalona, el candidato popular conoce y aprovecha muy bien las pautas y los tiempos mediáticos, a la vez que incentiva un discurso contundente y de fuerte posicionamiento; mientras que, en L'Hospitalet, parece que es el medio de comunicación el que quiere abrir un debate que los partidos prefieren evitar o confinar a discusiones muy neutras.

Como ya hemos mencionado al inicio, las pautas de García Albiol son reconocidas por el anterior alcalde, Jordi Serra, que admite que la estrategia comunicativa del dirigente conservador busca una consecuencia política a largo plazo -buena muestra de ello es que Albiol repitió victoria en 2015 y, tras serle arrebatada la alcaldía, el partido lo premió con la candidatura a la Generalitat, incluso sabiendo, o quizá por ello, que el cariz del discurso del ex primer edil es conocido incluso a nivel estatal — y señala que este viene hablando de inmigración «desde hace siete u ocho años» (BN, 17 de mayo de 2011, recogiendo el debate del programa Àgora de TV3), con lo cual admite su habilidad politizadora. Quizá 
con la investigación que hemos realizado no podemos hablar directamente de las consecuencias electorales del discurso, pero sí podemos resaltar que existe un tipo de eficacia política: la que atañe a la subida en importancia de la figura de García Albiol dentro de su propio partido y la escalada hacia su liderazgo en un ámbito autonómico. L'Hospitalet supone un contrapunto, porque el agenda setting no está tan marcado por los partidos ni hay un liderazgo personal tan relevante: el uso y el marcado de la agenda es más fruto de la labor periodística o incluso de los agentes sociales mencionados en las noticias que de las propias formaciones concurrentes, quizá con la excepción de PxC, que resulta un caso especialmente llamativo, puesto que logra dos concejales pese a que su presencia mediática sea absolutamente testimonial, lo cual no hace sino confirmar la intuición de que, en L'Hospitalet, el discurso se fraguó en buena medida en la calle.

La campaña electoral, por su dinámica especial, en la que el emisor adquiere todo el protagonismo (puesto que es tiempo de hacer propuestas), parece la época idónea precisamente para que no se introduzcan nuevas dinámicas de cuestionamiento del discurso, sino que se apuntale ese racismo de élite que hemos subrayado anteriormente. Se puede hacer de forma descarnada, como en Badalona, sin embargo "tecnificar» un asunto controvertido, como en el caso de L'Hospitalet, quizá sea diferente desde el punto de vista del agenda setting, pero no lo es desde el análisis crítico del discurso. Y desde luego, en ambos casos, y por el sesgo inherente a la elaboración de las piezas, el medio recoge y refuerza una tendencia que es común: la invisibilización de quienes deberían ser los principales agentes activos de las noticias: los propios inmigrantes. La contraparte al discurso de ataque a la inmigración es, como mucho, un organismo no gubernamental del tipo SOS Racismo o Unescocat. Por otro lado, la representación acrítica del discurso preventivo de las administraciones (y nos referimos nuevamente a ese presunto intento «despolitizador» o minimizador del conflicto en el caso de L'Hospitalet, que pondría la legislación por delante) hacia la inmigración no favorece una representación equilibrada de los hechos (Bañón, 2002: 286) y presenta la discusión en términos nominalistas (inseguridad versus incivismo), negándose a tratar integralmente la problemática. La propia dinámica de campaña agrava ese desequilibrio, por mucho que el discurso parezca más coral y atenuado que en el caso de Badalona.

La emergencia de figuras como García Albiol o de discursos como el de L'Hospitalet, que aluden a la gestión de la inmigración, emana de la problematización indirecta del fenómeno que recogen encuestas como los barómetros del CIS, que, a su vez, beben de cierta imaginería, proporcionada por los medios de comunicación, que asocia la inmigración casi exclusivamente con la irregularidad (barcazas, saltos a la valla, etc.), además de hacer uso de sustantivos del tipo avalancha o de aludir explícitamente a la nacionalidad de quienes cometen determinados delitos (como hemos visto especialmente en el caso de los gitanos rumanos en Badalona). Ni mucho menos nos encontramos ante las épocas en las que los barómetros del CIS tipificaban la inmigración como uno de los principales problemas de la sociedad española con porcentajes altos — destaca el barómetro de septiembre de 2006, en el que el 59\% 
de los encuestados lo colocaba en primera posición, por delante del paro, que suele estar en cabeza- (Cea D'Ancona y Valles Martínez, 2010: 478-479). Sin embargo, su politización y problematización ya han calado en el modo de abordarla discursivamente por parte de medios, de políticos — en todos los niveles de gobierno - y de la propia sociedad.

Por supuesto, la investigación tiene algunas limitaciones: cuantificar la repercusión y confirmar algunas de las hipótesis acerca del comportamiento electoral en ambas localidades implicaría haber realizado un diseño de investigación diferente, como un estudio de panel. También sería interesante profundizar en el calado discursivo y conocer la posible influencia de los fenómenos detectados comparando las encuestas anteriores a las elecciones con otras posteriores, o bien extender el análisis a la prensa y a la radio locales o autonómicos, con el fin de que la muestra fuera cuantitativamente superior y permitiera sacar unas conclusiones de mayor peso en lo concerniente a ver cómo se solapa el agenda setting dentro de distintos escalafones en el sistema de medios de comunicación. Incluso sería una buena idea realizar un estudio de continuidad de las primeras pautas aquí detectadas para irnos hasta las elecciones locales de 2015. Cabe igualmente profundizar en las dinámicas sugeridas desde una perspectiva enteramente de análisis crítico del discurso, que aquí solo hemos esbozado como contrapunto a un discurso pretendidamente aséptico.

Del mismo modo, ya hemos señalado que los tres términos derivados de la teoría del agenda setting (el propio agenda setting, framing y priming) están aún en discusión y, en el caso del segundo, hubiera cabido la posibilidad bien de considerarlo mero attribute agenda setting ligado a la adjetivación de los fenómenos - aunque, en el caso que nos ocupa, esto sería prácticamente un debate nominalista-, o bien de operacionalizarlo de maneras diferentes. Asimismo, el terreno queda abonado para que se analicen otros fenómenos que aquí se han mencionado someramente, como el attribute priming, analizándolo de un modo sistemático.

\section{Referencias bibliográficas}

Bañón, Antonio (2002). Discurso e inmigración: Propuestas para el análisis de un debate social. Murcia: Universidad de Murcia. Servicio de Publicaciones.

Bañón Hernández, Antonio (ed.) (2007). Discurso periodistico y procesos migratorios. Donostia: Tercera Prensa.

Berrocal, Salomé (coord.) (2003). Comunicación politica en televisión y nuevos medios. Barcelona: Ariel.

Brown, Bartram Stewart (1992). The United States and the politicization of the World Bank: Issues of international law and policy. Londres: Kegan Paul International.

Buonfino, Alessandra (2004). «Between Unity and Plurality: The Politicization and Securitization of the Discourse of Immigration in Europe». New Political Science [en línea], 26 (1), 23-49. <http://dx.doi.org/10.1080/0739314042000185111>.

Cea D’Ancona, M. a Ángeles y Valles Martínez, Miguel S. (2010). Xenofobias y xenofilias en clave biográfica: Relatos entrelazados de autóctonos y foráneos. Madrid: Siglo XXI. 
DufFIELD, Mark (2004). Las nuevas guerras en el mundo global: La convergencia entre desarrollo y seguridad. Madrid: Los Libros de la Catarata.

Entman, Robert Matthew (1993). «Framing: Toward Clarification of a Fractured Paradigm». Journal of Communication [en línea], 43 (4), 51-58. <http://dx.doi.org/10.1111/j.1460-2466.1993.tb01304.x>.

Freidenberg, Flavia; D’Adamo, Orlando y García Beaudoux, Virginia (1999). «Medios de comunicación y política: Un estudio del efecto de priming durante una campaña electoral». Entrecaminos. Washington: Georgetown University Center for Latin American Studies, 4, 133-150.

Gamson, William Anthony y Modigliani, Andre (1989). «Media Discourse and Public Opinion on Nuclear Power: A Constructionist Approach». American Journal of Sociology [en línea], 95 (1), 1-37. <http://dx.doi.org/10.1086/229213>.

Ghanem, Salma (1997). "Filling in the tapestry: The second level of agenda setting». En: McCombs, Maxwell; Shaw, Donald Leslie y Weaver, David (eds.). Communication and Democracy. Mahwah (NJ): Erlbaum, 3-14.

Hopmann, David Nicolas; Elmelund-Praestekaer, Cristian; Albaek, Erik; Vliegenthart, Rens y De Vreese, Claes H. (2010). «Party media agenda-setting: How parties influence election news coverage». Party Politics [en línea], 18, 173-191. <http:// dx.doi.org/10.1177/1354068810380097>.

Iyengar, Shanto (1991). Is Anyone Responsible?: How Television Frames Political Issues [en línea]. Chicago: University of Chicago Press. <http://dx.doi.org/10.7208/ chicago/9780226388533.001.0001>.

Iyengar, Shanto y Kinder, Donald R. (1987). News that matters. Chicago: University of Chicago Press.

Iyengar, Shanto; Peters, Mark D. y Kinder, Donald R. (1982). «Experimental Demonstrations of the "Not So-Minimal" Consequences of Television News Programs». The American Political Science Review [en línea], 76 (4), 848-858. <http://dx.doi.org/10.2307/1962976>.

KIm, Sei-Hill; Han, Miejeon; Doo-Hun, Choi y KIm, Jeong-Nam (2012). «Attribute agenda setting, priming and the media's influence on how to think about a controversial issue». International Communication Gazette [en línea], 74 (1), 43-59. <http://dx.doi.org/10.1177/1748048511426991>.

Kim, Sei-Hill; Scheufele, Dietram A. y Shanahan, James (2002). "Think about it this way: Attribute agenda-setting function of the press and the public's evaluation of a local issue». Journalism \& Mass Communication Quarterly [en línea], 79 (1), 7-25. <http://dx.doi.org/10.1177/107769900207900102>.

MaAreK, Philippe J. (2009). Marketing político y comunicación. Barcelona: Paidós.

McCombs, Maxwell E. y Shaw, Donald L. (1972). «The Agenda Setting Function of Mass Media». Public Opinion Quarterly [en línea], 36 (2), 176-187. <http://dx.doi.org/10.1086/267990>.

Noëlle-Neumann, Elizabeth (1974). «The Spiral of Silence: A theory of public opinion». Journal of Communication [en línea], 24 (2), 43-51. <http://dx.doi.org/10.1111/j.1460-2466.1974.tb00367.x>.

Pericot i Canaleta, Jordi y Capdevila, Arantxa (2009). L'espectre del tripartit: Comunicació politica i comportament electoral a les eleccions catalanes del 2006. Girona: Documenta Universitaria. 
Pericot i Canaleta, Jordi; Capdevila Gómez, Arantxa y Pintor Iranzo, Iván (2007). Las estrategias persuasivas en la campaña electoral de las elecciones al Parlament de Catalunya de 2003. Congreso AECPA. Documento de trabajo.

Price, Vincent y Tewksbury, David (1997). "News values and public opinion: A theoretical account of media priming and framing». En: BARETT, G. A. y BosTER, F. J. (eds.). Progress in communication sciences: Advances in persuasion, 13, 173-212. Greenwich (CT): Ablex.

SÁdAba, Teresa (2006). Framing: Una teoría para los medios de comunicación. Pamplona: Ulzama.

Scheufele, Dietram A. y Tewksbury, David (2007). «Framing, Agenda Setting and Priming: The Evolution of Three Media Effects Models». Journal of Communication [en línea], 57, 9-20. <http://dx.doi.or g/10.1111/j. 0021-9916.2007.00326.x>.

Shoemaker, Pamela J. y Reese, Stephen D. (1996). Mediating the message: Theories of influences mass media content. 2. ${ }^{\mathrm{a}}$ ed. White Plains (NY): Longman.

VAN DijK, Teun A. (1997). Racismo y análisis crítico de los medios. Barcelona: Paidós Ibérica.

- (2003a). Racismo y discurso de las élites. Barcelona: Gedisa.

- (2003b). Dominación étnica y racismo discursivo en España y América Latina. Barcelona: Gedisa.

Wright, Susan (1998). "The Politicization of Culture». Anthropology Today [en línea], 14 (1), 7-15.

<http://dx.doi.org/10.2307/2783092>. 